\title{
Digital Fault Locator for Double End Fed Transmission Lines
}

\author{
R. Micheletti \\ Department of Energy and Systems Engineering \\ University of Pisa \\ Largo L. Lazzarino, 156122 Pisa (Italy) \\ Tel. (+39 050) 2217349, Fax (+39 050) 2217333 \\ E-mail: roberto.micheletti@dsea.unipi.it
}

\begin{abstract}
The paper presents a digital fault locator by dynamic system parameter estimation for a double end fed transmission line. The method uses about 1/6 cycle of recorded fault data and doesn't require filtering of dc offset and high-frequency components. The system differential equations are based on a lumped parameter line model, Thevenin equivalents at both ends of the line and an unknown fault resistance. The accuracy is demonstrated by a representative set of tests results obtained with computer simulation.
\end{abstract}

\section{Key words}

Fault location, Transmission lines, Parameter estimation.

\section{Introduction}

Transmission line faults must be located quickly and accurately in order to repair the faulted section, restore power delivery and reduce outage time as soon as possible. Therefore the development of fast and accurate fault location techniques has become a highly important research area. Several papers have been published in recent years on fault location methods. Most of them involve two main approaches. One is based on the travelling wave theory. When a line fault occurs a sudden change in voltage or in current at the fault point generates high frequency components. Fault generated travelling waves appear as disturbances superimposed on the power frequency signals; by processing these signals, recorded by the relays, it is possible to determine the fault distance. However this method depends on the travelling wave propagation, that is a complex phenomenon difficult to analyze perfectly; this is critical to the accuracy of the fault location [1]-[3].

The other approach relies on information supplied by the line currents and voltages at some observation points on an energized system within the first instants after fault inception [4]. In both cases the recordings of voltage and current constitutes the initial data for an estimation problem leading to fault location.

Most fault locating devices measure impedance, or more exactly reactance, between the short circuit and the end of the line where they are installed. The measured reactance provides an exact distance to the faulted point when the fault resistance is zero. This latter, unfortunately is not zero in actual faults, causing the impedance to deviate from its true value. This is because the current that flows through the fault resistance is slenderly shifted in phase with respect to the current measured at the end of the line, due to the effect of the prefault load current. As a result, the fault resistance is recognized as an apparent impedance with both resistive and reactive components, which is responsible for an error in the fault location. The error may be positive or negative, depending on the direction of the load current. Many algorithms that correct this error were presented [5]-[10]. Further publications on fault locacation can be found in [11]-[13]. In this paper another way of producing fast and accurate fault location is proposed. The line is represented as a lumped parameter circuit. The system model includes Thevenin equivalents with resistances and inductances at both ends of the line and an unknown fault resistance. A method of dynamic parameter estimation will be used in this paper to find fault distance. The fault location is quickly obtained by comparing the response of the actual system with that of the lumped parameter model. The model's parameters are varied until an adequate 
match is obtained with the actual system response. This procedure permits to estimate not only the fault distance but also the fault resistance which may be or may not be of interest.

\section{System model}

The most complete representation of the system model includes not only the series impedances but also the parallel parameters of the line. Generally the shunt conductance is neglected due to its very small contribution to the shunt admittance; moreover, for transmission lines less than about $100 \mathrm{~km}$ long, the effect of the earth capacitance on the power frequency component is very small and is usually neglected. Furthermore neither the high frequency transient components due to the capacitance, immediately after a fault occurs, effect in a negative way the estimation process if a model without capacitance representation is used and the sampling rate of the signals is at least twice the highest frequency of the observed transient components. Therefore in this analysis it has not been taken into account the shunt admittance of the line.

The overall system model is shown in fig. 1, where both ends of the line are represented by three-phase Thevenins equivalents for transient.

$\mathrm{V}_{\mathrm{a} 0}$ and $\mathrm{V}_{\mathrm{b} 0}$ are the instantaneous voltages of the Thevenin equivalents at the measurement and remote ends of the line, respectively. Similarly $Z_{a}(p)$ and $Z_{b}(p)$ are the the operational impedances $(\mathrm{p}=\mathrm{d} / \mathrm{dt})$ of the Thevenin equivalents at the measurement and remote ends of the line, respectively.

$\mathrm{Z}(\mathrm{p})=(\mathrm{R}+\mathrm{Lp})$ and $\mathrm{R}_{\mathrm{f}}$ are the operational line impedance per kilometer and the fault resistance, respectively, while $1_{0}$ is the total line length.

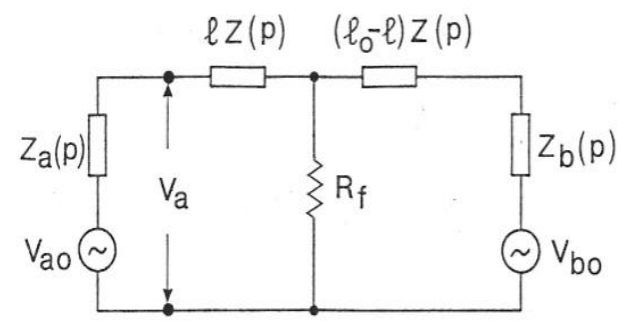

Fig.1 Faulted system configuration

All types of faults that are likely to occur on a threephase power system can be led back to the study of a single phase equivalent circuit in which the relation between the parameter of the equivalent system and real system, that depends on the type of fault (3 phase, phase-phase, phase-ground), is obtained by appropriately altering the sequence network's interconnection. By application of the superposition principle to fig. 1 , the fault voltages and currents can be resolved into prefault (fig. 2) and fault caused components (fig. 3)

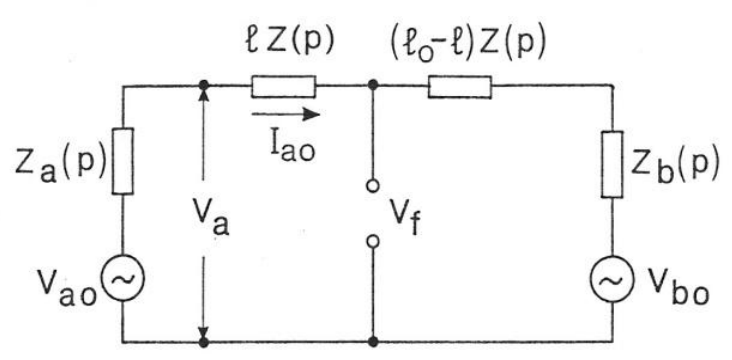

Fig. 2 Prefault circuit

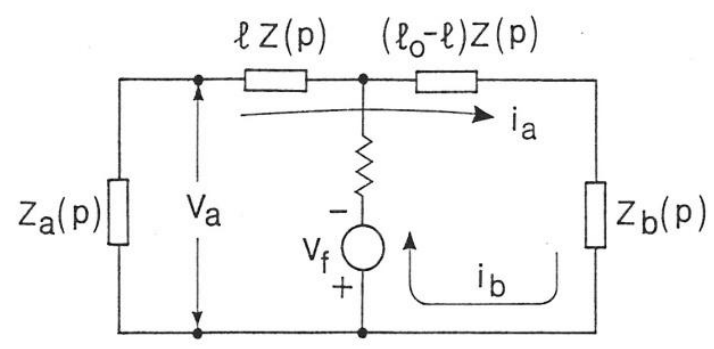

Fig. 3 Circuit describing fault caused variables

If the fault occurs at distance 1 from the measuring point, the prefault sinusoidal voltage at fault location $V_{f}$ and the fault caused currents can be expressed, in terms of $\mathrm{R}_{\mathrm{f}}$ and 1 , both in steady-state systems and under transient systems conditions.

In particular the operational impedances of the Thevenin equivalents behind the measurement point are eliminated by inserting the observable voltage $V_{a}$. The expression of $V_{f}$ can be written

$$
\begin{aligned}
& \overline{\mathrm{V}}_{\mathrm{f}}=\overline{\mathrm{V}}_{\mathrm{a}}-(1 \mathrm{R}-\mathrm{jl} \omega \mathrm{L}) \overline{\mathrm{I}}_{\mathrm{a} 0} \\
& \mathrm{v}_{\mathrm{f}}(\mathrm{t})=\sqrt{2} \mathrm{~V}_{\mathrm{f}} \sin \left(\omega \mathrm{t}+\theta_{\mathrm{f}}\right)
\end{aligned}
$$

where $\mathrm{V}_{\mathrm{f}}$ and $\theta_{\mathrm{f}}$ are function of $\overline{\mathrm{V}}_{\mathrm{a}}, \mathrm{I}_{\mathrm{a} 0}$ and 1 .

Moreover the expressions of the fault caused currents can be written in terms of $V_{f}, R_{f}$ and 1 .

$$
\mathrm{i}_{\mathrm{a}}(\mathrm{t})=\mathrm{C}_{1 \mathrm{a}} \mathrm{e}^{\mathrm{p}_{1} \mathrm{t}}+\mathrm{C}_{2 \mathrm{a}} \mathrm{e}^{\mathrm{p}_{2} \mathrm{t}}+\mathrm{C}_{3 \mathrm{a}} \sin (\omega \mathrm{t})+\mathrm{C}_{4 \mathrm{a}} \cos (\omega \mathrm{t})
$$$$
\mathrm{i}_{\mathrm{b}}(\mathrm{t})=\mathrm{C}_{1 \mathrm{~b}} \mathrm{e}^{\mathrm{p}_{1} \mathrm{t}}+\mathrm{C}_{2 \mathrm{~b}} \mathrm{e}^{\mathrm{p}_{2} \mathrm{t}}+\mathrm{C}_{3 \mathrm{~b}} \sin (\omega \mathrm{t})+\mathrm{C}_{4 \mathrm{~b}} \cos (\omega \mathrm{t})
$$

where $\mathrm{C}_{1 \mathrm{a}}, \mathrm{C}_{2 \mathrm{a}}, \mathrm{C}_{3 \mathrm{a}}, \mathrm{C}_{4 \mathrm{a}}, \mathrm{C}_{1 \mathrm{~b}}, \mathrm{C}_{2 \mathrm{~b}}, \mathrm{C}_{3 \mathrm{~b}}, \mathrm{C}_{4 \mathrm{~b}}, \mathrm{p}_{1}, \mathrm{p}_{2}$ are function of $\mathrm{V}_{\mathrm{f}}, \mathrm{R}_{\mathrm{f}}$ and $\mathrm{l}$.

In the parameter estimation process the voltage $\mathrm{V}_{\mathrm{a}}$ and the current $I_{a 0}$ in the model are the known inputs derived from the recorded data of the real circuit while the current $i_{a}$, forming the model output, is compared with the corresponding current obtained from the the 
recorded real line fault caused current in order to find the unknown parameters 1 and $\mathrm{R}_{\mathrm{f}}$.

\section{Estimation Algorithm}

The equation describing the fault caused current $i_{a}(t)$ can be expressed as a function of the parameters $1, R_{f}$ and time $\mathrm{t}$

$$
\mathrm{i}_{\mathrm{a}}(\mathrm{t})=\mathrm{i}_{\mathrm{a}}\left(1, \mathrm{R}_{\mathrm{f}}, \mathrm{t}\right)
$$

Expanding $\mathrm{i}_{\mathrm{a}}(\mathrm{t})$ in a Taylor series in the neighborhood of given values $1^{*}, \mathrm{R}_{\mathrm{f}} *$ of parameters $1, \mathrm{R}_{\mathrm{f}}$ gives

$$
\mathrm{i}_{\mathrm{a}}(\mathrm{t})=\mathrm{i}_{\mathrm{a}}(\mathrm{t})_{\alpha}+\left[\frac{\partial \mathrm{i}_{\mathrm{a}}(\mathrm{t})}{\partial \mathrm{l}}\right]_{\alpha} \Delta \mathrm{l}+\left[\frac{\partial \mathrm{i}_{\mathrm{a}}(\mathrm{t})}{\partial \mathrm{R}_{\mathrm{f}}}\right]_{\alpha} \Delta \mathrm{R}_{\mathrm{f}}
$$

where the higher order terms of the expansion are ignored and $\alpha=\left(1^{*}, \mathrm{R}_{\mathrm{f}}^{*}\right)$.

The principle of operation of the estimation technique is based, as above mentioned, on the comparison between the real values of the fault current at measurement end of the line and the estimation values of the model output [14]-[15].

Thus the problem consists in determining the parameters $1, \mathrm{R}_{\mathrm{f}}$ able to minimize the error between real sampled values and estimation values. If the input quantities are sampled with sampling rate $f_{S}$, a set of $n$ samples is obtained.

The error, at instant $t_{\mathrm{S}}$, is expressed as

$\mathrm{e}\left(\mathrm{t}_{\mathrm{S}}\right)=\left[\mathrm{i}_{\mathrm{ar}}\left(\mathrm{t}_{\mathrm{s}}\right)-\mathrm{i}_{\mathrm{a}}\left(\mathrm{t}_{\mathrm{S}}\right)\right]$

where $i_{a}\left(t_{s}\right)$ and $i_{a r}\left(t_{s}\right)$ represent the sampled outputs of the model reference and the real system at the measuring point at time $t_{\mathrm{S}}$. The total square error is given by

$E=\sum_{s=1}^{n}\left[i_{a r}\left(t_{s}\right)-i_{a}\left(t_{s}\right)\right]$

Substitution of (4) into (6) yields

$$
\begin{aligned}
E=\sum_{\mathrm{s}=1}^{\mathrm{n}} & \left\{\mathrm{i}_{\mathrm{ar}}\left(\mathrm{t}_{\mathrm{s}}\right)-\mathrm{i}_{\mathrm{a}}\left(\mathrm{t}_{\mathrm{s}}\right)_{\alpha}-\left[\frac{\partial \mathrm{i}_{\mathrm{a}}\left(\mathrm{t}_{\mathrm{s}}\right)}{\partial \mathrm{l}}\right]_{\alpha} \Delta \mathrm{l}+\right. \\
& \left.-\left[\frac{\partial \mathrm{i}_{\mathrm{a}}\left(\mathrm{t}_{\mathrm{s}}\right)}{\partial \mathrm{R}_{\mathrm{f}}}\right]_{\alpha} \Delta \mathrm{R}_{\mathrm{f}}\right\}^{2}
\end{aligned}
$$

The total square error is minimized by solving the partial derivatives of (7) relative to 1 and $R_{f}$ evaluated at $1^{*}$ and $\mathrm{R}_{\mathrm{f}} *$

$$
\frac{\partial \mathrm{E}}{\partial \mathrm{l}}=0 \quad \frac{\partial \mathrm{E}}{\partial \mathrm{R}_{\mathrm{f}}}=0
$$

There results after rearrangement

$$
\begin{aligned}
& \sum_{\mathrm{s}=1}^{\mathrm{n}}\left[\frac{\partial \mathrm{i}_{\mathrm{a}}\left(\mathrm{t}_{\mathrm{s}}\right)}{\partial \mathrm{l}}\right]_{\alpha}\left[\mathrm{i}_{\mathrm{ar}}\left(\mathrm{t}_{\mathrm{s}}\right)-\mathrm{i}_{\mathrm{a}}\left(\mathrm{t}_{\mathrm{s}}\right)\right]_{\alpha} \\
& =\sum_{\mathrm{s}=1}^{\mathrm{n}}\left[\frac{\partial \mathrm{i}_{\mathrm{a}}\left(\mathrm{t}_{\mathrm{s}}\right)}{\partial \mathrm{l}}\right]_{\alpha}\left\{\left[\frac{\partial \mathrm{i}_{\mathrm{a}}\left(\mathrm{t}_{\mathrm{s}}\right)}{\partial \mathrm{l}}\right]_{\alpha} \Delta \mathrm{l}+\right. \\
& \left.+\left[\frac{\partial \mathrm{i}_{\mathrm{a}}\left(\mathrm{t}_{\mathrm{s}}\right)}{\partial \mathrm{R}_{\mathrm{f}}}\right]_{\alpha} \Delta \mathrm{R}_{\mathrm{f}}\right\}
\end{aligned}
$$

$$
\begin{aligned}
& \sum_{\mathrm{s}=1}^{\mathrm{n}}\left[\frac{\partial \mathrm{i}_{\mathrm{a}}\left(\mathrm{t}_{\mathrm{s}}\right)}{\partial \mathrm{R}_{\mathrm{f}}}\right]_{\alpha}\left[\mathrm{i}_{\mathrm{ar}}\left(\mathrm{t}_{\mathrm{s}}\right)-\mathrm{i}_{\mathrm{a}}\left(\mathrm{t}_{\mathrm{s}}\right)\right]_{\alpha} \\
& =\sum_{\mathrm{s}=1}^{\mathrm{n}}\left[\frac{\partial \mathrm{i}_{\mathrm{a}}\left(\mathrm{t}_{\mathrm{s}}\right)}{\partial \mathrm{R}_{\mathrm{f}}}\right]_{\alpha}\left\{\left[\frac{\partial \mathrm{i}_{\mathrm{a}}\left(\mathrm{t}_{\mathrm{s}}\right)}{\partial \mathrm{l}}\right]_{\alpha} \Delta \mathrm{l}+\right. \\
& \left.+\left[\frac{\partial \mathrm{i}_{\mathrm{a}}\left(\mathrm{t}_{\mathrm{s}}\right)}{\partial \mathrm{R}_{\mathrm{f}}}\right]_{\alpha} \Delta \mathrm{R}_{\mathrm{f}}\right\}
\end{aligned}
$$

This system can be written in compact form

$$
\begin{aligned}
& c_{11} \Delta \mathrm{l}+\mathrm{c}_{12} \Delta \mathrm{R}_{\mathrm{f}}=\mathrm{b}_{1} \\
& \mathrm{c}_{21} \Delta \mathrm{l}+\mathrm{c}_{22} \Delta \mathrm{R}_{\mathrm{f}}=\mathrm{b}_{2}
\end{aligned}
$$

where cjk and $\mathrm{bj}$ are known values and $\Delta \mathrm{l}$ and $\Delta \mathrm{R}_{\mathrm{f}}$ are the unknown of the linear system. Solution of system (10) gives the corrections $\Delta \mathrm{l}$ and $\Delta \mathrm{R}_{\mathrm{f}}$ necessary for updating parameters 1 and $R_{\mathrm{f}}$ for each iteration step.

\section{Computer Simulation Results}

A $80 \mathrm{~km}$ transmission line model was used for testing the fault location algorithm by computer simulation. The model power system is similar to fig. 1, with parameter data taken from a typical $275 \mathrm{kV}$ transmission line, given in Table 1.

Table 1 - $275 \mathrm{kV}, 400$ MVA transmission line model parameters

\begin{tabular}{|l|l|}
\hline Line resistance & $0.078 \Omega / \mathrm{km}$ \\
\hline Line reactance & $0.338 \Omega / \mathrm{km}$ \\
\hline
\end{tabular}

To cover various situations in actual power systems, computer simulations have been carried out extensively 
in order to determine the minimum data window required to locating a fault with good accuracy.

The elaboration for generating new values of 1 and $R_{f}$ each iteration step is carried out on a set of 3 samples of the input quantities, which are sampled with sampling ratio $\mathrm{f}_{\mathrm{s}}=5 \mathrm{kHz}$, corresponding to 100 samples per period.

The fault inception was selected such that both high frequency components and dc offset in the recorded fault current are present.

Fig. 4 shows the waveforms of currents $i_{a}, i_{a r}$ and error $\left(i_{a r}-i_{a}\right)$ for a fault distance of $40 \mathrm{~km}$ and fault resistance of $30 \Omega$.
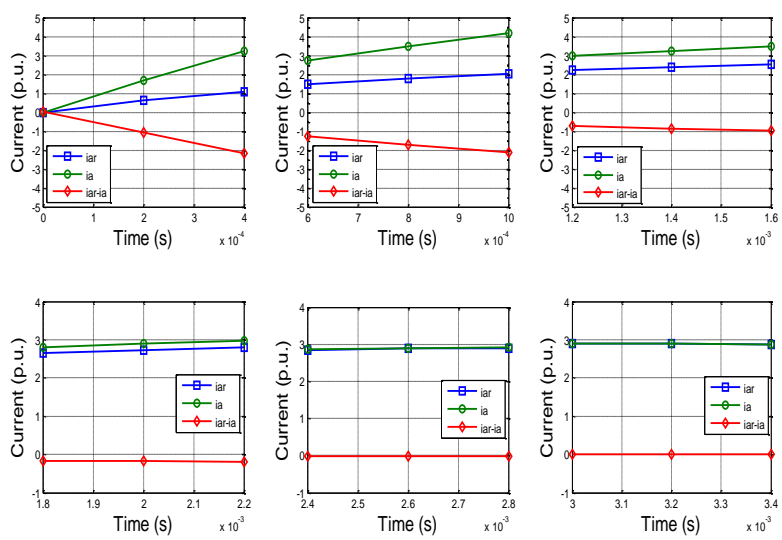

Fig. 4 Waveforms of currents $i_{a}, i_{a r}$ and error $\left(i_{a r}-i_{a}\right)$

Typical convergence characteristics are shown in fig. 5 for a fault distance of $40 \mathrm{~km}$ and fault resistance of $30 \Omega$. The initial estimates for fault distance and fault resistance are chose near zero; six iteration steps are required to get to the convergence

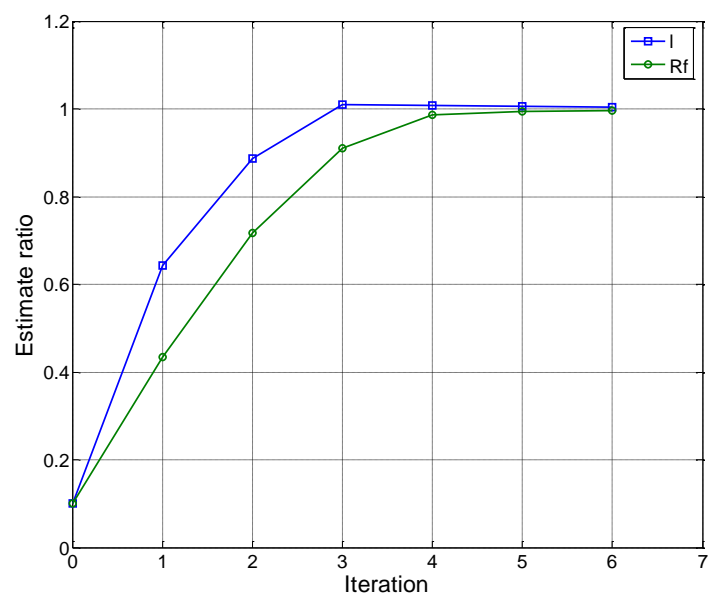

Fig. 5 Convergence of the estimation algorithm

$\operatorname{Rf}(=30 \Omega) \quad$ converges to $29.87 \Omega$

1 (= $40 \mathrm{~km})$ converges to $40.15 \mathrm{~km}$
Fig. 6 shows the ratio of estimate to true value of the distance against the data window width for three values of the fault resistance $(1 \Omega, 30 \Omega, 100 \Omega)$ with an actual fault distance of $40 \mathrm{~km}$.

The accuracy of the distance estimate is within $0.7 \%$ in each case.

Resistances over $100 \Omega$ have not been considered because might not be detected as a fault at all because of the relatively small fault current.

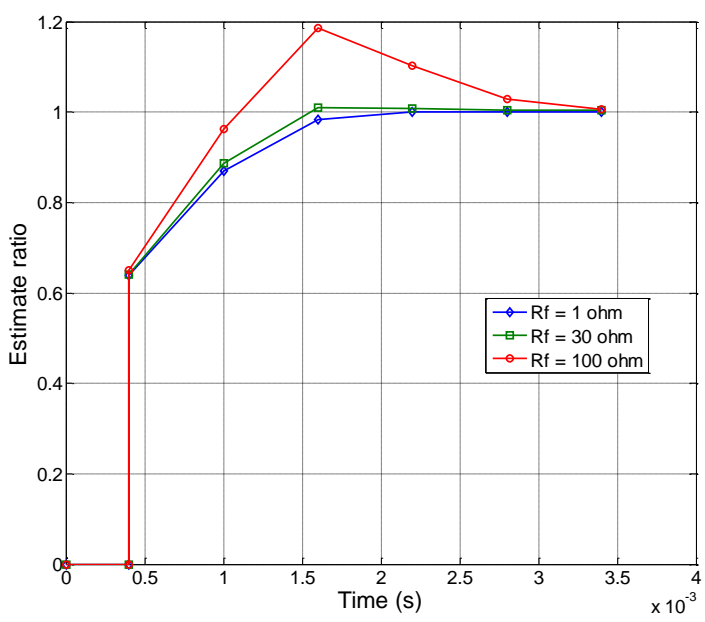

Fig. 6 Effect of fault resistance on location accuracy at $1=40 \mathrm{~km}$

$$
\begin{array}{ll}
\mathrm{Rf}=1 \Omega & \text { converges to } 40.05 \mathrm{~km} \\
\mathrm{Rf}=30 \Omega & \text { converges to } 40.15 \mathrm{~km} \\
\mathrm{Rf}=100 \Omega & \text { converges to } 40.28 \mathrm{~km}
\end{array}
$$

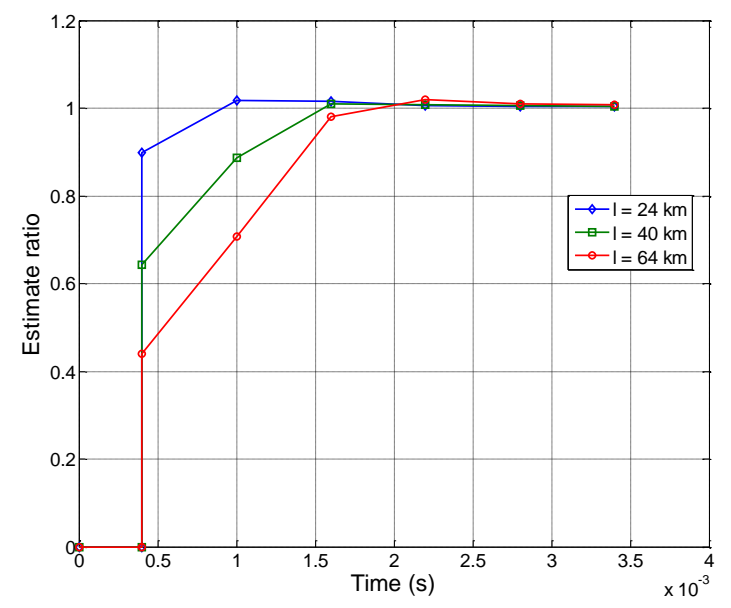

Fig. 7 Effect of fault location distance on location accuracy at $\mathrm{Rf}=30 \Omega$

$$
\begin{array}{ll}
1=24 \mathrm{~km} & \text { converges to } 24.09 \mathrm{~km} \\
1=40 \mathrm{~km} & \text { converges to } 40.15 \mathrm{~km} \\
1=64 \mathrm{~km} & \text { converges to } 64.50 \mathrm{~km}
\end{array}
$$


Fig.7 shows estimates for several fault distances, 24, 40 and $64 \mathrm{~km}$ with $30 \Omega$ fault resistance; the final estimates are within $0.8 \%$ accuracy in each case.

Line switchings and load changes may cause variations in the actual value of the Thevenin operational impedances at the remote end of the line.

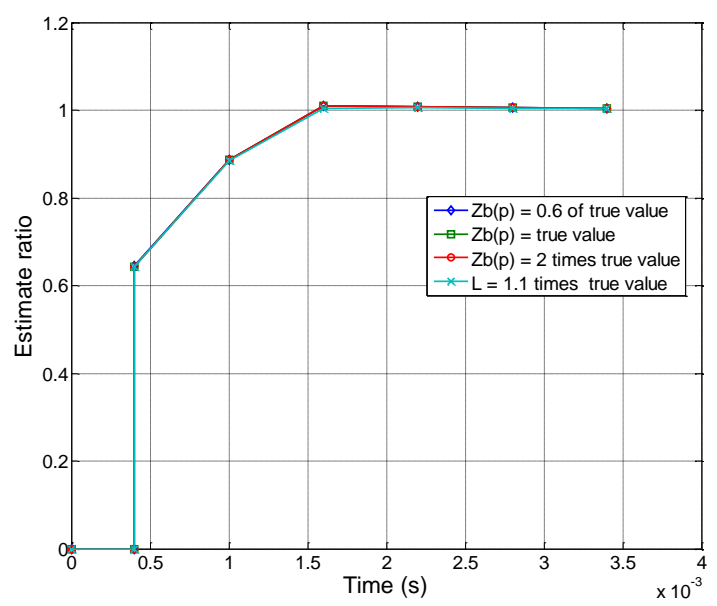

Fig. 8 Effect of errors in $\mathrm{Zb}(\mathrm{p})$ and $\mathrm{L}$ on location accuracy at $\mathrm{Rf}=30 \Omega$ and $\mathrm{l}=40 \mathrm{~km}$

$\mathrm{Z}_{\mathrm{b}}(\mathrm{p})=0.6$ of true value $\mathrm{Z}_{\mathrm{b}}(\mathrm{p})=$ true value

converges to $40.15 \mathrm{~km}$ converges to $40.15 \mathrm{~km}$ $\mathrm{Z}_{\mathrm{b}}(\mathrm{p})=2$ times true value converges to $40.15 \mathrm{~km}$ $\mathrm{L}=1.1$ times true value converges to $40.13 \mathrm{~km}$

Fig. 8 shows the effects of using a value for Thevenin impedance $Z_{b}(p)$ in the estimator that is $60 \%$ of the actual value used in the simulation studies; in a second test the Thevenin impedance $\mathrm{Z}_{\mathrm{b}}(\mathrm{p})$ is assumed to be twice the actual value.

The same figure shows also the effect of errors in the value of the line impedance $L$, caused by variations of earth resistivity along the line.

As observed from fig. 8 the final estimates of the fault distance, that was actually $40 \mathrm{~km}$ with a fault resistance of $30 \Omega$, are within $0.4 \%$ accuracy in each case and are practically insensitive to variations both of the Thevenin operational impedance $Z_{b}(p)$ both of the line impedance L.

\section{Conclusion}

The paper has described an algorithm for the extremely rapid and accurate location of faults on high voltage transmission line.

Useful estimates of fault distance are obtained using about 1/6 cycle of recorded fault data at the measurement end of the line.

The method doesn't require filtering of dc offset and high-frequency components from the recorded signals and can be used for any type of fault on a three-phase transmission line by appropriately altering the sequence networks' interconnection.

No information about fault resistance is required apriori for the algorithm to work.

The sources of errors due to the parallel parameters of the line have not been included in the analysis.
Computer simulation tests indicate that fault location accuracy is relatively insensitive to fault resistance and fault distance. Moreover during these tests it has been taken into account the effect of the errors introduced by measurement instrumentation.

\section{References}

[1] A.O. Ibe, B.J. Cory: "A traveling wave-based fault locator for two and three terminal networks", Proc. of Power Industry Computer Application Conference (PICA), San Francisco, California, USA, May 6-10, 1985.

[2] Q. Jiang, C. Xiangxun, Z. Jinchao: "Travelling wave fault location on transmission line using wavelet transform" Proc. of Power System Technology Conference, POWERCOM '98, Beijing, China, Aug. 18-21,1998, pp. 533-537

[3] M. Silva, M. Oleskovicz, D.V. Coury: "A fault locator for transmission lines using traveling waves and wavelet transform theory" $8^{\text {th }}$ IEE Int. Conference on Developments in Power System Protection, April 5-8, 2004, Vol. 1, pp. 212-215

[4] M.T. Sant, M.E. Paithankar: "On line digital fault locator for overhead transmission lines", Proc. IEE, Vol. 126, No. 11, November 1979, pp. 1181-1185.

[5] L. Eriksson, M. M. Saha, G.D. Rockefeller: " An Accurate Fault Locator with Compensation for Apparent Reactance in the Fault Resistance Resulting from RemoteEnd Infeed," IEEE Transactions on Power Apparatus and Systems, Vol. PAS-104, No. 2, pp. 424-436, 1985

[6] K. Takagi, Y. Yomakoshi, M. Yamaura, R. Kondow, and T. Matsushima: "Development of a new type fault locator using the one terminal voltage and current data," IEEE Trans. Power App. Syst., vol. PAS-101, pp.2892-2898, Aug. 1982.

[7] A. Girgis, D. Hart, W. Peterson: "A new fault location technique for two- and three-terminal lines," IEEE Trans. Power Delivery, vol. 7, pp.98-107, Jan. 1992.

[8] M. Abe, T. Emura, N. Otsuzuki, M. Takeuchi: "Development of a new fault location system for multi-terminal single transmission lines," IEEE Trans. Power Delivery, vol. 10, pp. 159-168, Jan. 1995.

[9] V. Cook.: "Fundamental aspect of fault location algorithms used in distance protection", Proc. IEE, Vol. 133, Pt. C, n. 6, September 1986, pp. 359-368.

[10] A. Isaksson: "Digital protective relaying through recursive least-square identification", Proc. IEE, Vol. 135, Pt. C, No. 5, September 1988, pp. 441-449.

[11] M. Djurić, Z. Radojević, V. Terzija: "Distance protection and fault location utilizing only phase current phasors," IEEE Trans. Power Delivery, vol. 13, pp. 1020-1026, Oct. 1998.

[12] D. Novosel, D.G. Hart, E. Udren, J. Garitty: "Unsynchronized Two- Terminal Fault Location Estimation", IEEE Trans. on Power Delivery, Vol. 11, No. 1, January 1996.

[13] T.S.Sidhu, at alii: "Bibliography of Relay Literature, 2007 IEEE Committee Report" IEEE Trans. Power Delivery, vol. 25, pp. 88-101, Jan. 2010.

[14] G.G. Richards, O.T. Tan: "An accurate fault location estimator for transmission lines", Trans. IEEE, Vol.PAS101, No.4, April 1982, pp 945-949.

[15] R. Micheletti: "Fast and accurate fault location estimator for power lines", 6th IMEKO TC-4 International Symposium: Intelligent Instrumentation for Remote and On-Site Measurements, Brussels, 12-14 May 1993, pp. 321-326. 